\title{
EFFECT OF EXTRUSION PROCESS AND VARIOUS ELONGATION RATIOS ON THE STRUCTURAL AND DIELECTRIC PROPERTIES OF PVDF-BASED COPOLYMER CONTAINING MICRO AND NANO-SIZED CRYSTALLITES
}

\author{
${ }^{1}$ Miroslav MRLÍK, ${ }^{1}$ Martin CVEK, ${ }^{1}$ Josef OSIČKA, ${ }^{2}$ Marcin MASLOWSKI, ${ }^{3}$ Pavel TOFEL \\ ${ }^{1}$ Tomas Bata University in Zlín, University Institute, Centre of Polymer Systems, Zlín, Czech Republic, EU, \\ mrlik@utb.cz \\ ${ }^{2}$ Lodz University of Technology, Institute of Polymer and Dye Technology, Lodz, Poland, EU \\ ${ }^{3}$ Brno University of Technology, Department of Physics, Faculty of Electrical Engineering and \\ Communication, Brno, Czech Republic, EU
}

https://doi.org/10.37904/nanocon.2020.3694

\begin{abstract}
In this contribution, the effect of the extrusion process of the poly(vinylidene fluoride-co-hexafluoropropylene) (PVDF-co-HFP) with the subsequent elongation/poling on its structural and dielectric properties is presented. The extrusion can be understood as continuous processing of polymer melts in the large scale (in comparison to solvent casting), when the thickness of the final product can be varied depending on the final operation conditions. Herein, the PVDF-co-HFP sheets of $5 \mathrm{~cm}$ in width were extruded using a single screw extruder. The fabricated sheets were cooled down and then, they were cut to the stripes and subsequently stretched to various elongations (100, 200 and $500 \%$ ) using a universal tensile testing machine. Such samples were investigated using FTIR in order to determine the effect of the elongation process on the transformation of the $\alpha$-phase to the $\beta$-crystalline phase. The extend of the electro-active $\beta$-phase was quantified and its impact on the dielectric properties was investigated. The results clearly demonstrated that the elongation has a crucial effect on the final dielectric properties of the PVDF-co-HFP.
\end{abstract}

Keywords: Poly(vinylidene fluoride), poly(vinylidene fluoride-co-hexafluoropropylene), extrusion, dielectric properties, electromechanical coupling

\section{INTRODUCTION}

Smart systems can be classified as materials that can actively respond to the external stimuli, such as the electric [1] or magnetic field [2], temperature [3], pH change [4], light stimulation [5] or mechanical vibration [6]. In the last years, the majority of the electrical machines undergo the damaging due to the vibrations from the bearings causing the mechanical perturbances [7]. Therefore, the detection of the unwanted vibrations seems to be a crucial point to extend the operating lifetime of the machines. From this point of view, the vibration sensors based on the piezoelectric ceramics are typical materials of choice [8]. The ceramic-based sensors however have some drawbacks such as high cost and brittleness [9]. Especially, the brittleness is a very negative property, which can significantly decrease the efficiency of this type of sensor [10].

Therefore, certain polymeric materials such as poly(vinylidene fluoride) (PVDF) started to be very attractive, since they can be easily processed, they are flexible and provide suitable piezoelectric capability required for the vibration sensing [11]. The main issue of the PVDF is its inherent property; the materials requires the additional treatment, otherwise the PVDF consist mainly the non-piezoelectric $\alpha$-phase [12]. By utilizing the elongation [13], polling in electric fields [14], particle addition [15] etc., the piezoelectric $\beta$-phase can be developed, and relatively good electromechanical coupling coefficients $\left(\mathrm{d}_{33} \sim 25 \mathrm{pC} / \mathrm{N}\right)$ can be achieved [16]. 
There are also other techniques of the PVDF post-processing that were successfully applied to increment the $d_{33}$ coefficients including the electrospinning [17], melt-electrowriting [18] or the extrusion [19].

Besides the PVDF, also its copolymers are very promising for this purpose. The poly(vinylidene-cohexafluoropropylene) (PVDF-co-HFP) is frequently used due to its good piezoelectric capability [20]. Its processing via the extrusion is however very limited, and just few research articles have addressed this topic [21], while only one paper was dealing with stretching during poling called SSP [22]. In the vast majority, this material is processed by solvent casting [23] or electrospinning [24]. From these reasons, this study is focused on the processing of the PVDF-co-HFP using industrially-viable extrusion process, and the impact of various relative elongations on the structural changes and dielectric properties.

\section{EXPERIMENTAL}

\subsection{Materials}

Poly(vinylidene-co-hexafluoropropylene) (PVDF-co-HFP) in the form of pellets (CAS number: 9011-17-0) with the molecular weight (Mw) of $\sim 400000 \mathrm{~g} / \mathrm{mol}$ (Sigma Aldrich, USA) was used to construct the tested elements.

\subsection{Characterization methods}

The extrusion process was performed at $190^{\circ} \mathrm{C}$ using twin-screw extruder (Scientific, China) and using flat die having $5 \mathrm{~cm}$ in width and $0.5 \mathrm{~mm}$ in thickness. The continuous sheet was collected and cooled down without any interventions at laboratory conditions.

Then, the sheets were cut using the steel templates to the form of stripes with $15 \mathrm{~mm}$ in width, $100 \mathrm{~mm}$ in length. Such stripes were elongated using the universal testing machine M350-5 CT (Testometric, Lancashire, UK) coupled with a heat chamber (Omron) operating at a temperature of $65^{\circ} \mathrm{C}$. The cross-head speed of the clamps was set to $10 \mathrm{~mm} / \mathrm{min}$, with the relative elongations of 50,100 and $300 \%$.

The Fourier-transform infrared spectroscopy (FTIR) was performed on Nicolet 6700 (Thermo-Scientific, USA) spectrometer equipped with ATR accessory and a germanium crystal. The spectra were recorded in a wavenumber range of $4000-500 \mathrm{~cm}^{-1}$ with a spectral increment of $2 \mathrm{~cm}^{-1}$.

Dielectric properties were measured on the neat as well as on the stretched samples using Broadband Dielectric Impedance Analyzer (Novocontrol, Montabaur, Germany), in the frequency range of $0.01 \mathrm{~Hz}$ to $10 \mathrm{MHz}$, using a standard sample cell BDCS 140.

The neat PVDF-co-HFP as well as the stretched analogues were poled using a custom-build apparatus at the electric field strength of $7 \mathrm{kV} / \mathrm{mm}$, and the temperature of $110^{\circ} \mathrm{C}$. Then, a thin conductive (silver) layer was deposited on the samples and their piezoelectric charge coefficient, $d_{33}$, was measured within 24 hour after the poling process. The $d_{33}$ was analyzed in the transversal mode using the electrometer $6517 \mathrm{~b}$ (Keithley, USA). Each sample was placed between two copper electrodes; the lower electrode had a diameter of $20 \mathrm{~mm}$, while the upper one had a diameter of $10 \mathrm{~mm}$. A mechanical force of $0.49 \mathrm{~N}$ was applied onto the upper electrode and the electric charge generated by the sample was recorded. Each sample was analyzed at ten positions, the presented $d_{33}$ values represent the average values from the obtained data.

\section{RESULTS AND DISCUSSION}

The PVDF-co-HFP has similar crystalline structure as the neat PVDF. For this material, the transformation of $\alpha$-phase to $\beta$-phase also plays a crucial role [25-27]. The typical main peaks of the $\alpha$-phase corresponding to $762 \mathrm{~cm}^{-1}$ and for the $\beta$-phase at $840 \mathrm{~cm}^{-1}$ as displayed in Figure 1. A magnified visualization (inset figure) provides definite information of the successful $\alpha$ - $\beta$-phase transformation. As clearly seen, neat PVDF-co-HFP shows a negligible peak at $840 \mathrm{~cm}^{-1}$ and with further elongation this peak clearly increases exhibiting the 
highest intensity for the sample with $300 \%$ deformation. On the other hand, the suppression of the $\alpha$-phase is similarly important. In this case, the visible decrease of the peak intensity and thus confirmation, that $\alpha-\beta-$ phase transition was successful, was easily distinguishable only for the sample with the elongation of $300 \%$. The other samples did not exhibit almost any changes in the $\alpha$-peak intensity, while slight decrease was observed for the sample that underwent the elongation of $100 \%$. This clearly indicates that extrusion process with consequent elongation has crucial impact on the distribution of the micro and nano-sized crystallites those presence is very important for development electro-active $\beta$-phase. Similar observation was also published on PVDF samples [28].

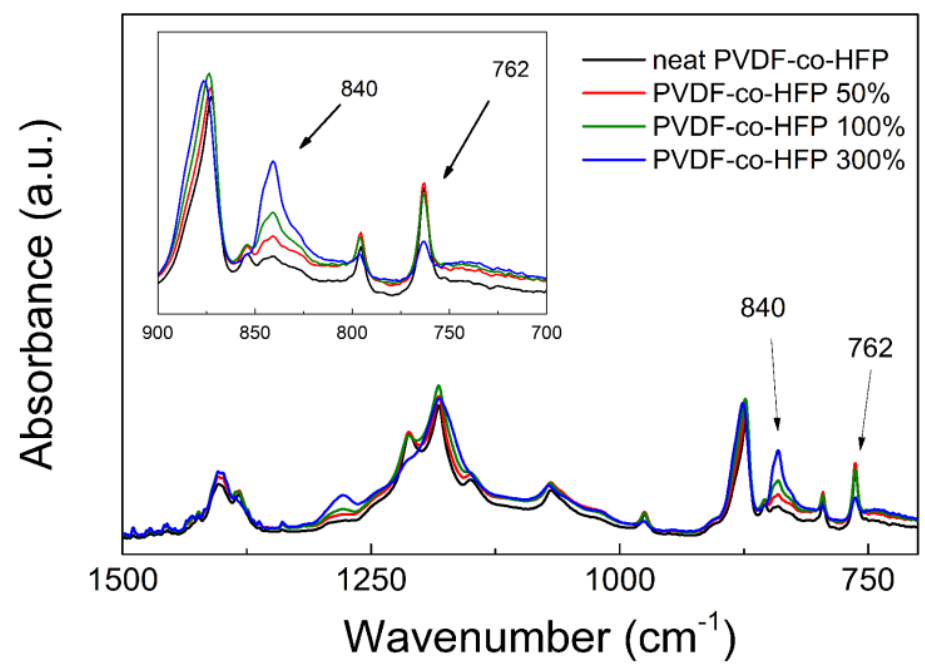

Figure 1 FTIR spectra of the PVDF-co-HFP samples before and after stretching process

Dielectric properties are assumed to be a crucial parameter affecting the electro-activity of the PVDF-co-HFPbased elements. Therefore, the relative permittivity was plotted against frequency; as obvious, the higher relative permittivity is achieved, therefore the better electrical output efficiency upon mechanical stimulation can be generated $[29,30]$. As can be seen in Figure 2, the relative permittivity measured on the prepared samples was increasing with the increasing deformation. This behavior demonstrates that the transformation of the $\beta$-phase was successful which is presented as a substantial increase of relative permittivity with higher strain deformation, and in fact, it confirms the trends obtained from the FTIR analysis.

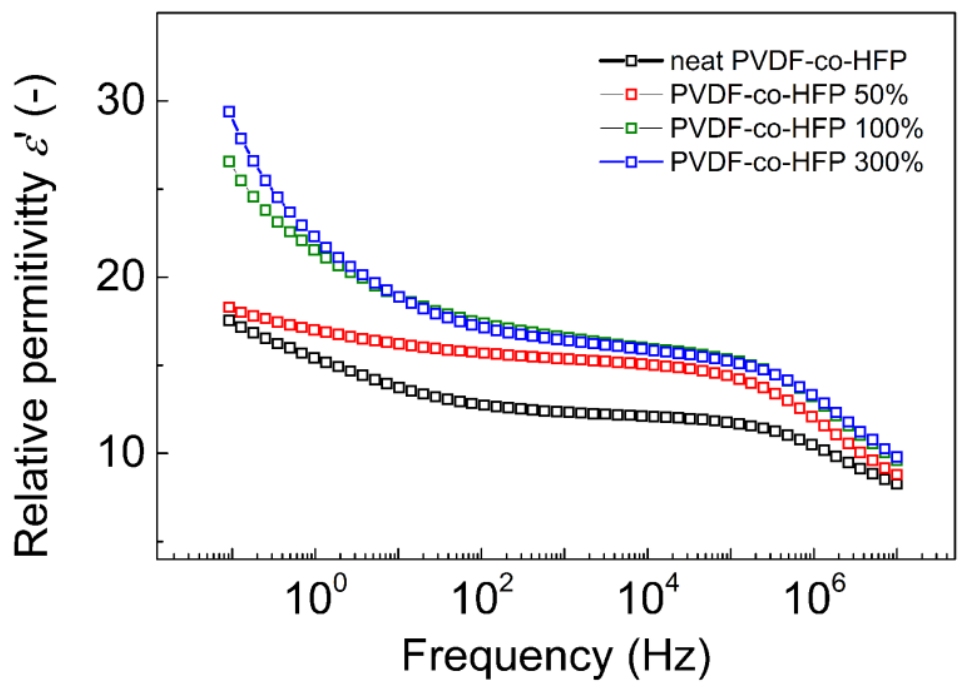

Figure 2 Dielectric spectra of relative permittivity against frequency of the PVDF-co-HFP samples before and after stretching/poling process 
Finally, the electromechanical activity of the investigated samples is presented in Table 1. The dataset confirms that the industrially extruded PVDF-co-HFP samples can be effectively treated to increment their piezo-activity via elongation and subsequent polling process at $7 \mathrm{kV} / \mathrm{mm}$. The maximal $\mathrm{d}_{33}$ values obtained for these materials upon the presented conditions are sufficient to show a comparable efficiency with the other commercial PVDF systems [31].

Table 1 Results of the piezo-activity for PVDF-co-HFP-based samples

\begin{tabular}{|c|c|c|c|}
\hline Sample ID & $\begin{array}{c}\text { Capacitance }(\mathbf{p F}) \text { at } \\
\mathbf{1 0 0} \mathbf{~ k H z}\end{array}$ & $\mathbf{d}_{33}$ coeficient (pC/N) & $\mathbf{d}_{33}{ }^{2} / \mathbf{e}_{33}$ \\
\hline neat PVDF-Co-HFP & 6.19 & 1.1 & 3.47 \\
\hline PVDF-co-HFP 50\% & 11.6 & 1.8 & 7.22 \\
\hline PVDF-co-HFP 100\% & 11.8 & 1.9 & 8.11 \\
\hline PVDF-co-HFP 300\% & 12.6 & 4.6 & 37.1 \\
\hline
\end{tabular}

${ }^{\text {a }}$ permittivity $e_{33}=C \times h / A$, where $C$ is the capacitance, $h$ is the sample thickness, and $A$ is the surface area

\section{CONCLUSION}

In this paper, the PVDF-co-HFP was extruded and further elongated using various deformations $(50,100$, and $300 \%$ ). Then, the materials were poled and investigated from their electro-activity point of view. It was confirmed that the elongation positively influenced the transformation of the non-piezoelectric $\alpha$-phase to its piezoelectric $\beta$-phase analogue, which was accompanied by increasing FTIR peak centered at $840 \mathrm{~cm}^{-1}$. Analogously, the dielectric properties, specifically, the relative permittivity also increased with the elongation factor. Finally, the electromechanical investigation proved that $d_{33}$ coefficient, and thus the effectivity of the systems was incremented, which was attributed to successfully developed $\beta$-phase. The most significant enhancement (4-fold) of $d_{33}$ was recorded for the PVDF-co-HFP elongated by $300 \%$. Finally have to be concluded, that extrusion process and consequent elongation positively influencing the distribution of the micro and nano-sized crystallites to form proper $\beta$-phase enhancing the vibration sensing effectivity for sample elongated by $300 \%$.

\section{ACKNOWLEDGEMENTS}

This work was supported by the Czech Science Foundation grant no. 19-17457S. The authors M. M. and J. O gratefully acknowledge the Ministry of Education, Youth and Sports of the Czech RepublicDKRVO (RP/CPS/2020/003) and finally, author M.C. would like to acknowledge project (RP/CPS/2020/006).

\section{REFERENCES}

[1] PLACHY, T.; SEDLACIK, M.; PAVLINEK, V.; STEJSKAL, J. The observation of a conductivity threshold on the electrorheological effect of p-phenylenediamine oxidized with p-benzoquinone. J. Mater. Chem. C. 2015, vol. 3, no. 38, pp. 9973-9980.

[2] CVEK, M.; MRLIK, M.; ILCIKOVA, M.; MOSNACEK, J.; BABAYAN, V.; KUCEKOVA, Z.; HUMPOLICEK, P.; PAVLINEK, V. The chemical stability and cytotoxicity of carbonyl iron particles grafted with poly (glycidyl methacrylate) and the magnetorheological activity of their suspensions. RSC Adv. 2015, vol. 5, no. 89, pp. 7281672824.

[3] LUBTOW, M.M.; MRLIK, M.; HAHN, L.; ALTMANN, A.; BEUDERT, M.; LUHMANN, T.; LUXENHOFER, R., Temperature-Dependent Rheological and Viscoelastic Investigation of a Poly(2-methyl-2-oxazoline)-b-poly(2-isobutyl-2-oxazoline)-b-poly(2-meth yl-2-oxazoline)-Based Thermogelling Hydrogel. J. Func. Biomater. 2019, vol. 10, no. 3, pp. 16. 
[4] MRLIK, M.; SPIREK, M.; AL-KHORI, J.; AHMAD, A.A.; MOSNACEK, J.; ALMAADEED, M.A.; KASAK, P. Musselmimicking sulfobetaine-based copolymer with metal tunable gelation, self-healing and antibacterial capability. Arab. J. Chem. 2020, vol. 13, no. 1, pp. 193-204.

[5] KRUPA, I.; SOBOLCIAK, P.; MRLIK, M. Smart Non-Woven Fiber Mats with Light-Induced Sensing Capability. Nanomaterials. 2020, vol. 10, no. 1, p. 13.

[6] JI, S.H.; YUN, J.S. Fabrication and Characterization of Aligned Flexible Lead-Free Piezoelectric Nanofibers for Wearable Device Applications. Nanomaterials. 2018, vol. 8, no. 4, p. 9.

[7] PEARSON, M.R.; EATON, M.J.; PULLIN, R.; FEATHERSTON, C.A.; HOLFORD, K.M. IOP, Energy Harvesting for Aerospace Structural Health Monitoring Systems. In: Modern Practice in Stress and Vibration Analysis 2012. lop Publishing Ltd: Bristol, 2012; Vol. 382.

[8] HE, Y.X.; YANG, Q.; LUO, M.D.; LIU, R.Y. Effect of the physical parameters of longitudinally polarized PZT tubes on PZT sensors. J. Phys. D-Appl. Phys. 2020, vol. 53, no. 27, p. 10.

[9] BAI, Y.; TOFEL, P.; PALOSAARI, J.; JANTUNEN, H.; JUUTI, J. A Game Changer: A Multifunctional Perovskite Exhibiting Giant Ferroelectricity and Narrow Bandgap with Potential Application in a Truly Monolithic Multienergy Harvester or Sensor. Adv. Mater. 2017, vol. 29, no. 29, p. 7.

[10] ZHANG, G.Z.; ZHAO, P.; ZHANG, X.S.; HAN, K.; ZHAO, T.K.; ZHANG, Y.; JEONG, C.K.; JIANG, S.L.; ZHANG, S.L.; WANG, Q. Flexible three-dimensional interconnected piezoelectric ceramic foam based composites for highly efficient concurrent mechanical and thermal energy harvesting. Energy Environ. Sci. 2018, vol. 11, no. 8, p. 12.

[11] YI, J.G.; LIANG, H. A PVDF-based deformation and motion sensor: Modeling and experiments. IEEE Sens. J. 2008, vol. 8, no. 3-4, pp. 384-391.

[12] WANG, Y.R.; ZHENG, J.M.; REN, G.Y.; ZHANG, P.H.; XU, C. A flexible piezoelectric force sensor based on PVDF fabrics. Smart Mater. Struct. 2011, vol. 20, no. 4, p. 7.

[13] SENCADAS, V.; GREGORIO, R.; LANCEROS-MENDEZ, S. alpha to beta Phase Transformation and Microestructural Changes of PVDF Films Induced by Uniaxial Stretch. J. Macromol. Sci. Part B-Phys. 2009, vol. 48, no. 3, pp. 514-525.

[14] PU, J.A.; YAN, X.J.; JIANG, Y.D.; CHANG, C.E.; LIN, L.W. Piezoelectric actuation of direct-write electrospun fibers. Sens. Actuator A-Phys. 2010, vol. 164, no. 1-2, pp. 131-136.

[15] AHN, Y.; LIM, J.Y.; HONG, S.M.; LEE, J.; HA, J.; CHOI, H.J.; SEO, Y., Enhanced Piezoelectric Properties of Electrospun Poly(vinylidene fluoride)/Multiwalled Carbon Nanotube Composites Due to High beta-Phase Formation in Poly(vinylidene fluoride). J. Phys. Chem. C. 2013, vol. 117, no. 22, pp. 11791-11799.

[16] TING, Y.; SUPRAPTO; NUGRAHA, A.; CHIU, C.W.; GUNAWAN, H., Design and characterization of one-layer PVDF thin film for a 3D force sensor. Sens. Actuator A-Phys. 2016, vol. 250, no., pp. 129-137.

[17] LEE, B.S.; PARK, B.; YANG, H.S.; HAN, J.W.; CHOONG, C.; BAE, J.; LEE, K.; YU, W.R.; JEONG, U.; CHUNG, U.I.; PARK, J.J.; KIM, O. Effects of Substrate on Piezoelectricity of Electrospun Poly(vinylidene fluoride)Nanofiber-Based Energy Generators. ACS Appl. Mater. Interfaces. 2014, vol. 6, no. 5, pp. 3520-3527.

[18] FLORCZAK, S.; LORSON, T.; ZHENG, T.; MRLIK, M.; HUTMACHER, D.W.; HIGGINS, M.J.; LUXENHOFER, R.; DALTON, P.D. Melt electrowriting of electroactive poly(vinylidene difluoride) fibers. Polym. Int. 2019, vol. 68, no. 4, pp. 735-745.

[19] MARTINS, P.; LOPES, A.C.; LANCEROS-MENDEZ, S. Electroactive phases of poly(vinylidene fluoride): Determination, processing and applications. Prog. Polym. Sci. 2014, vol. 39, no. 4, pp. 683-706.

[20] ADHIKARY, P.; GARAIN, S.; MANDAL, D. The co-operative performance of a hydrated salt assisted sponge like P(VDF-HFP) piezoelectric generator: an effective piezoelectric based energy harvester. Phys. Chem. Chem. Phys. 2015, vol. 17, no. 11, pp. 7275-7281.

[21] HUAN, Y.; LIU, Y.Y.; YANG, Y.F.; WU, Y.N. Influence of extrusion, stretching and poling on the structural and piezoelectric properties of poly (vinylidene fluoride-hexafluoropropylene) copolymer films. J. Appl. Polym. Sci. 2007, vol. 104, no. 2, pp. 858-862.

[22] KUMAR, A.; PERLMAN, M.M. Simultaneous stretching and corona poling of PVDF and P(VDF-TriFE) films .2. J. Phys. D-Appl. Phys. 1993, vol. 26, no. 3, pp. 469-473. 
[23] FRUBING, P.; WANG, F.P.; WAGENER, M. Relaxation processes and structural transitions in stretched films of polyvinylidene fluoride and its copolymer with hexafluoropropylene. Appl. Phys. A-Mater. Sci. Process. 2012, vol. 107, no. 3, pp. 603-611.

[24] SHI, L.; WANG, R.; CAO, Y.M. Effect of the rheology of poly(vinylidene fluoride-co-hexafluropropylene) (PVDFHFP) dope solutions on the formation of microporous hollow fibers used as membrane contactors. J. Membr. Sci. 2009, vol. 344, no. 1-2, pp. 112-122.

[25] LI, H.X.; ZHANG, W.X.; DING, Q.; JIN, X.Y.; KE, Q.F.; LI, Z.L.; WANG, D.; HUANG, C. Facile Strategy for Fabrication of Flexible, Breathable, and Washable Piezoelectric Sensors via Welding of Nanofibers with Multiwalled Carbon Nanotubes (MWCNTs). ACS Appl. Mater. Interfaces. 2019, vol. 11, no. 41, pp. 38023-38030.

[26] CAI, J.; HU, N.; WU, L.K.; LIU, Y.H.; LI, Y.; NING, H.M.; LIU, X.Y.; LIN, L.Y. Preparing carbon black/graphene/PVDF-HFP hybrid composite films of high piezoelectricity for energy harvesting technology. Compos. Pt. A-Appl. Sci. Manuf. 2019, vol. 121, no., pp. 223-231.

[27] GAUR, A.; SHUKLA, R.; BRAJESH, K.; PAL, A.; CHATTERJI, S.; RANJAN, R.; MAITI, P. Processing and nanoclay induced piezoelectricity in poly(vinylidene fluoride-co-hexafluoro propylene) nanohybrid for device application. Polymer. 2016, vol. 97, pp. 362-369.

[28] GERHARD, R. IEEE, Improving essential properties of dielectrics for electro-electrets, piezo-electrets and ferroelectric polymer electrets via physico-chemical routes. In: Proceedings of the 2013 leee International Conference on Solid Dielectrics. leee: New York, 2013; pp 45-48.

[29] KOC, M.; PARALI, L.; SAN, O. Fabrication and vibrational energy harvesting characterization of flexible piezoelectric nanogenerator (PEN) based on PVDF/PZT. Polym. Test. 2020, vol. 90, p. 10.

[30] SAHOO, R.; MISHRA, S.; UNNIKRISHNAN, L.; MOHANTY, S.; MAHAPATRA, S.; NAYAK, S.K.; ANWAR, S.; RAMADOSS, A. Enhanced dielectric and piezoelectric properties of Fe-doped ZnO/PVDF-TrFE composite films. Mater. Sci. Semicond. Process. 2020, vol. 117, p. 9.

[31] MRLIK, M.; LEADENHAM, S.; ALMAADEED, M.A.; ERTURK, A. Figure of merit comparison of PP-based electret and PVDF-based piezoelectric polymer energy harvesters. In: Active and Passive Smart Structures and Integrated Systems 2016. Park, G., Ed. Spie-Int Soc Optical Engineering: Bellingham, 2016, Vol. 9799. 